\title{
STUDIES ON THE NATURAL HYDROPHOBIC BINDERS OF FLABELLIFERINS AND THEIR EFFECT ON SOME BIOACTIVITIES
}

\author{
INOKA ULUWADUGE ${ }^{1 *}$, A. A. PUNYA KEERTHI ${ }^{2}$, SEVVANDI N. SENADHEERA ${ }^{2}$ and E. R. JANSZ ${ }^{2}$ \\ ${ }^{1}$ Department of Biochemistry \& Clinical Chemistry, Faculty of Medicine, University of Kelaniya, Ragama. \\ ${ }^{2}$ Department of Biochemistry, Faculty of Medical Sciences, University of Sri Jayawardenapura, Nugegoda.
}

(Accepted: 21 December 2004)

\begin{abstract}
The fruit pulp and flour of Palmyrah (Borassus Flabellifer L.) contain flabelliferins (steroidal saponins) which are found naturally bound to hydrophobic molecules which give them a blue fluorescence in ultra violet (UV) light. These hydrophobic molecules have been isolated and have been found to be carotenoids, most probably phytofluene and phytoene. The presence of these binders modulate the bioactivity of flabelliferins. That is, they lower ATPase inhibition activity of flabelliferin-II (F-II) and increase the anti-microbial activity of flabelliferin-B ( $F-B)$ against Escherichia coli (ATCC 25922).
\end{abstract}

Key words: bioactivity, flabelliferins, natural hydrophobic binders, palmyrah, phytoene, phytofluene.

\section{INTRODUCTION}

Palmyrah (Borassus flabellifer L.) fruit pulp and flour contain steroidal saponins, flabelliferins ${ }^{1}$. These flabelliferins gave a blue fluorescence under the UV light and it was due to another compound binding the $\beta$-sitosterol moiety as the latter is not fluorescent. ${ }^{2}$ The binder can be removed by a toluene/methanol gradient in Medium Pressure Liquid Chromatography ${ }^{2}$ (MPLC) and by a gradient of methanol:n-propanol (1:1) mixture in a chromatotron. ${ }^{3}$

Flabelliferins are known to be bioactive. For example,flabelliferin-II (F-II), a tetraglycoside reduces weight gain ${ }^{2}$ and glucose uptake ${ }^{4}$ in mice. Flabelliferin-B (F-B), a triglycoside, inhibits yeast and a range of bacteria. ${ }^{5}$

Therefore, this study was carried out to investigate the nature of the binder and to determine its effect on binding F-II and F-B and their respective bioactivities.

\section{MATERIALS AND METHODS}

Palmyrah fruit pulp (PFP): Pulp from fruits from different sources was manually extracted with water (1: 2). ${ }^{1}$

Separation of Flabelliferins:Flabelliferins were isolated by the methods described previously ${ }^{1}$ and the binder was removed by eluting in methanol: $n$ propanol (1:1) in a chromatotron. ${ }^{4}$

Instruments for analysis: The instruments used were MPLC ${ }^{6}$ with a solvent gradient ${ }^{2}$, chromatotron ${ }^{4}$ for separating free and bound carotenoids and flabelliferins. UV absorbance was measured by a Shimadzu automatic reading double beam spectrophotometer model UV 1601. Densitometry was conducted on a Shimadzu CS $9301 \mathrm{PC}$ which is an UV /VIS variable dual wavelength flying spot scanning densitometer together with a fluorescent attachment.

High-Pressure Liquid Chromatography (HPLC) analysis was carried out using Waters HPLC system. This was used with Waters symmetry $\mathrm{C}_{18}, 5 \mu \mathrm{m}, 3.9 \times 150 \mathrm{~mm}$ column, 515pump system and a 2487 dual absorbance detector.

The optical density of the microbial studies was measured by using the Thermo spectronic spectrophotometer (spectronic educator), used as a nephliometer.

Preparation of intestinal mucosal samples: Mice were anesthetized using diethyl ether.

${ }^{*}$ Corresponding author 
Immediately after, the jejunum of each mouse was excised and was washed with cold saline $(50 \mathrm{ml})$. Each jejunum was cut into $5 \mathrm{~cm}$ segments and were placed in cold saline. Each of the segments were then cut open, the mucosal surfaces were blotted by pressing between two sheets of filter paper and were then scraped using a glass slide. The scrapings were collected into $2.5 \mathrm{ml}$ cold sucrose-EDTA medium. The mixture was homogenized and its volume was adjusted to 50 $\mathrm{ml}$ with more of the sucrose-EDTA medium. This medium contained intestinal $\mathrm{Na}^{+} / \mathrm{K}^{+}$ATPase activity.?

Effect of bitter $F$-II on the intestinal $\mathrm{Na}^{+} / \mathrm{K}^{+} A T^{\text {pase }}$ activity ${ }^{8}$ : Samples containing $\mathrm{Na}^{+} / \mathrm{K}^{+}$ATPase activity were prepared as described above. Test reaction mixture $(1.0 \mathrm{ml})$ was incubated with $\mathrm{MgCl}_{2}(5 \mathrm{mM}), \mathrm{NaCl}_{2}(100 \mathrm{mM}), \mathrm{KCl}(10 \mathrm{mM}), \mathrm{ATP}$ (3 mM), Tris-HCl ( $\mathrm{pH} 7.4$ ) and F-II at doses of 0.1 $\mathrm{mg}, 0.2 \mathrm{mg}$ and $0.3 \mathrm{mg}$ and $0.15 \mathrm{mg}, 0.3 \mathrm{mg}$ and $0.6 \mathrm{mg}$ for F-II (without binder) with binder respectively. The control reaction mixture contained the same reactants but with no F-II. The resulting inorganic phosphate was converted to phosphomolybdate with ammonium molybdate reagent $(1 \mathrm{ml}, 50 \mathrm{~g} / \mathrm{L})$. This was reduced with aminonapthosulphonic (ANS) acid $(0.5 \mathrm{ml}, 2 \mathrm{~g} / \mathrm{L})$ to produce a blue colour (molybdous acid), which was measured at a $\lambda$ of $680 \mathrm{~nm}$. Inorganic phosphate concentration was calculated from a standard curve $\left(\mathrm{r}^{2}=0.9896\right)$ and an $\mathrm{IC}_{50}$ value was determined.

Microbial studies: Escherichia coli (E.coli) - ATCC 25922 was obtained from the Medical Research Institute (MRI) of Sri Lanka and was maintained on agar slopes containing $1.5 \%$ agar, $1 \%$ glucose, $0.4 \%$ peptone and $0.2 \%$ beef extract, by subculturing every two weeks. F-B trials in liquid medium were prepared containing the same nutrient composition as above. Varying quantities of F-B (with and without the UV binder) $5-40 \mathrm{mg}$, were used. Test and control samples were prepared with an equal volume of sterilized water. The total volume was $5 \mathrm{ml}$. This was introduced under sterile conditions into sterilized test tubes (with cotton wool stoppers). The test tubes used were specific to the spectrophotometer, which was used for absorbance measurements. The absorbances were measured daily at a $\lambda$ of 700 nm (scatter peak) using a medium blank. The growth was followed for five days.

The Bauer-Kirby dise method ${ }^{9}$ was also used. After $24 \mathrm{~h}$, the inhibition zones of the test samples (with both equal weight and equal molar amounts of F-B with and without the binder) were measured.

\section{RESULTS}

\section{Nature of the binder}

Studies using extracts of PFP with MPLC have shown that a white compound with blue fluorescence eluted before the yellow carotenoids. It had a $\lambda_{\max }$ of $331 \mathrm{~nm}$ compatible with that of phytofluene. ${ }^{10}$ On isolation of the flabelliferin binder complex and subjecting it to elution on a chromatotron with methanol:n-propanol (1:1), the fractions collected contained a blue fluorescent substance. This on dissolving in acetonitrile:methanol: tetra hydrofuran (58:35:7), a carotenoid HPLC mobile phase which was used as it was known that fluorescent carotenoid were present in PFP, gave a yellow precipitate. This which is most likely oxidized-polymerised carotenoids, was separated by filtration to yield a colourless sclution with intense blue fluorescence. On subjecting this to Reverse Phase Highpressure Liquid Chromatography (RP-HPLC), a single peak was obtained prior to the retention time of hydrophobic coloured carotenoids on a $\mathrm{C}_{18}$ reverse phase column. The r.r.t. corresponded to standard phytofluene and had the same absorption spectrum with a $\lambda_{\max }$ at $331 \mathrm{~nm}$. Other spectroscopic instruments (for example Mass Spectrometer) were not available to confirm identity.

Subjecting crude flabelliferins to Freparative TLC yielded a blue mild fluorescent band, which gave a $\lambda_{\max }$ of $280 \mathrm{~nm}$. Flabelliferins bound to this compound gave a $\lambda_{\text {max }}$ of $278 \mathrm{~nm}$, showing that there is some distortion to the molecule on binding. Measuring absorbance with a variable wavelength spectrophotometer and densitometer gave a good absorbance around 280 $\mathrm{nm}$ but no peak at $330 \mathrm{~nm}$. Using a densitometer 
with fluorescent detection with excitation at 330 $\mathrm{nm}$ gave only small peaks (high fluorescence was expected), using a 300-400 $\mathrm{nm}$ filter indicating that phytofluene was a minor component. From the strong absorbance at $280 \mathrm{~nm}$ on the spectrophotometer, it seems likely that the major component could be the carotenoid phytoene. This is supported by further evidence that a natural hydrophobic binder separated from F-II by the chromatotron, gave a $\lambda_{\max }$ at $279 \mathrm{~nm}$ and not at $331 \mathrm{~nm}$.

\section{Bioactivity studies}

\section{Inhibition of ATP ase}

The $\mathrm{IC}_{50}$ of $\mathrm{F}$-II with and without the carotenoid is given in Table 1. This shows that the presence of the binder leads to inhibitory activity.

Table 1: Effect of binder on ATPase inhibition

\begin{tabular}{cc}
\hline Compound & $\mathrm{IC}_{50}(\mu$ moles $/ \mathrm{L})$ \\
\hline F-II & 0.5 \\
F-II and binder & 0.9 \\
\hline
\end{tabular}

Note: Tests were conducted in duplicate after plotting the P $i$ released versus the concentration in each case and determining the $50 \%$ inhibition value.

Liberation of $\mathrm{P} i$ was measured over $5 \mathrm{~min}$ in the presence and in the absence of the binder using varying amounts $(0.15 \mathrm{mg}$ to $0.26 \mathrm{mg})$ of flabelliferin and graphs of $\mathrm{P} i$ formed versus concentrations were plotted. F-B was not used for full inhibition studies as it did not show any inhibition in preliminary studies and this is confirmed by the finding of a previous study ${ }^{4}$ that F-B in PFP had no effect on glucose uptake by mice.

\section{Antimicrobial activity}

F-B without the UV binder gave an $\mathrm{IC}_{50}$ value of $31 \mu \mathrm{mol} / \mathrm{L}$ in solution. However, with the nonpolar binder F-B was less soluble in water and gave a cloudy solution to which the bacteria adhered to and gave a precipitate within 24 hours. Thus the $\mathrm{IC}_{50}$ of $\mathrm{F}-\mathrm{B}$ with the binder could not be calculated. At concentrations of which F-B showed full inhibition, an agar plate streaking showed no bacterial growth. However, the precipitate with F-B/binder/bacteria, on streaking on an agar plate showed growth.

Therefore, the Bauer-Kirby method had to be used. This gave larger inhibition zones for the F-B/binder complex compared to pure F-B. This is despite diffusional and solubility limitations. This was so when comparing both equal weight and equi-molar quantities (Table 2). F-II was not used in antimicrobial studies as it had been previously shown that its inhibitory properties are much lower than F-B. ${ }^{5}$

\section{Changes in properties}

The binder changes the following physical properties of F-B and also all other flabelliferins.

1. Decreased solubility in water.

2. Increased solubility in methanol.

3. Increased $R_{\mathrm{f}}$ in TLC spots.

4. The TLC spot is observed as disc shaped (not rounded like in the case of pure flabelliferins).

\section{DISCUSSION}

The evidence indicates that, it is very likely that the blue-fluorescent naturally occurring hydrophobic binder of F-II is mainly phytofluene.

Table 2: Inhibition zones of F-B with and without the binder

\begin{tabular}{llcc}
\hline & & $\mu$ moles/disc & Inhibition zone (mm) \\
\cline { 2 - 4 } Equi molar & F-B & 9.20 & $8^{*}$ \\
& F-B and binder & 9.20 & $14^{*}$ \\
Equal weights & F-B & 9.20 & $8^{*}$ \\
& F-B and binder & 5.66 & $13^{*}$ \\
\hline
\end{tabular}

\footnotetext{
${ }^{*}$ Results are an average of three readings by the disc method.
} 
It is probable that the other $280 \mathrm{~nm}$ binder is phytoene from UV-spectrum. ${ }^{10}$ Phytoene is present only in minor quantities in PFP and has not been isolated from flabelliferins. The fact that F-B with binder is fluorescent points to phytofluene as the major binder in F-B. Further Jayaweera and co-workers ${ }^{11}$ have shown by molecular modeling that phytoene and phytofluene, unlike other carotenoids, can form a stable complex with $\beta$-sitosterol (the aglycone of flabelliferins) by getting inserted into the cavity between the tail of the steroid and its ring system. This makes the entity more hydrophobic and will explain its solubility and TLC properties.

The lowering of inhibition of ATPase can be explained by two factors. (1) The presence of the carotenoid binder distorts the active carbohydrate moiety of F-II (Uluwaduge and Jayaweera, 2004 unpublished results), making it more difficult to bind to the inhibition site. (2) The insertion of the carotenoids increases the effective radius of the inhibitory molecule ${ }^{11}$, which also results in the lowering of inhibition of ATP ${ }^{\text {ase }}$. On the contrary, the decreased inhibition of $E$.coli was not clear as the opposite effect was expected. However, two factors need to be considered. Firstly, saponins inhibit microbes by penetrating the phospholipid bilayer (PLB) and causing a formation of a pore in the membrane from which $\mathrm{K}^{+}$leaks out. ${ }^{12}$ This contributes to the cause of death of the bacteria. Migration through the PLB will be facilitated by the presence of the non-polar carotenoid binder and this increases the inhibition. Secondly, there are reports that $\beta$ glucose linked $\alpha-1,4$ and $\alpha-1,2$ to rhamnose is a potent group for microbial inhibition, no matter what the parent aglycone is..$^{13,14,15}$ This group is present in $\mathrm{FB}^{2}$. It appears feasible that having effectively penetrated the PLB with the aid of the hydrophobic binder, this active carbohydrate moiety could interact with some other yet unknown vital biochemical system causing lethality at low concentrations.

\section{Acknowledgment}

The authors thank IPICS for grant SRI:07, Industrial Technology Institute for the use of their densitometer and MRI for E.coli type culture ATCC 25922.

\section{References}

1. Jansz E. R., Nikawala J. K., Guneratne M. J. \& Theivendirarajah K. (1994). The bitter principle and debittering of palmyrah fruit pulp. Journal of Science of Food and Agriculture 65: 185-189.

2. Ariyasena D. D. (2002). The diversity, bioactivity and structural studies of flabelliferins from palmyrah. MPhil Thesis. University of Sri Jayawardenapura.

3. Ariyasena D. D., Nikawala J. K., Jansz E. R. \& Abeysekara A. M. (2000). Separation techniques of flabelliferins from palmyrah (Borassus flabellifer L.) fruit pulp. Journal of Science, Eastern University of Sri Lanka 1: 1-9.

4. Uluwaduge I., Jansz E. R. \& Thabrew M. I. (2004). Effect of the bitter flabelliferin and its UV active binder of palmyrah (Borassus flabellifer L.) fruit pulp on intestinal ATPase and glucose uptake of mice. Chemistry in Sri Lanka 2. $27-28$.

5. Nikawala J. K., Wijeyaratne S. C., Jansz E. R. \& Abeysekara A. M. (1998). Flabelliferins, steroidal saponins from palmyrah fruit (Borassus flabellifer) pulp. II. Preliminary studies on effect on yeast and bacteria. Journal of the National Science Council of Sri Lanka 25: 141-150.

6. Ariayasena D. D., Jansz E. R. \& Beckstrom P. (2002). Direct Isolation of flabelliferins from palmyrah by MPLC. Journal of the National Science Foundation of Sri Lanka 30: 55-60.

7. Fujita M., Matsui H., Nagano K. \& Nakao M. (1971). Asymmetric distribution of Oubain sensitive ATPase activity in rat intestinal mucosa. Biochimica et Biophysica Acta 233: 404-408.

8. Brown A. M. (1982). ATPase determination in red blood cells In: The red cell membranes - a methodological approach. (Ed. J. C. Ellory) Academic Press. NewYork, pp 223-237.

9. Bauer A. W., Kirby W. M. M., Sherris J. C. \& Turch M. (1966). Antibiotic susceptibility testing by a standardizing disk method. American Journal of Clinical Pathology 45: 493-496. 
10. Rodriquesz-Aruaya D. B. (1999). In: A guide to carotenoid analysis in foods. ILSI Press Washington, pp 1-20.

11. Jayaweera P. M., Chandrika U. G. \& Jansz E. R. (2004). Computational evidence for the reversible Non-electrostatic hydrophobic binding of â-sitosterol with acyclic Carotenes. Chemistry in Sri Lanka 21: 26-27.

12. Melzig M. F., Bader G. \& Loose R. (2001). Investigations of the mechanism of membrane activity of selected triterpenoid saponins. Planta Medica 67: 43-48.
13. Dong M., Feng X. Z., Wu L.J., Wang G. \& Ikajima T. (2001). Two new steroidal saponins from the rhizomes of Dioscorea panthica and their cytotoxic activity. Planta Medica 67: 853857.

14: Kim H. K., Jeon W. K. \& Ko B. S. (2001). Flavanone glycosides from Citrus junos and their anti-influenza virus activity. Planta Medica 67 : 545-549.

15. Mimaki Y., Takashi Y., Kuroda M., Sashida Y. \& Nikaido T. (1996). Steroidal saponins from Nolina recurvata stems and their inhibitory activity on cyclic AMP phosphodiesterase. Phytochemistry 42: 1609-1615. 